\title{
O INDIVÍDUO PRESO NA ARMADILHA DA ESTRUTURA ESTRATÉGICA
}

Eugène Enriquez

Professor e Diretor do DEA e do Curso de Doutorado em Sociologia da Universidade de Paris VII, Diretor Adjunto do Laboratório de Mudança Social da Universidade Paris VII. Conferencista na EẢESP/FGV no $2^{\circ}$ semestre de 1996.

Artigo publicado originalmente sob o título L'individu pris au piège de la structure stratégique, na Revista Connexions, Toulouse: Erès, n. 54, 145-161, 1989.

Tradução: Marcelo Dantas, jornalista e administrador público, professor da Universidade Federal da Bahia, doutorando na Universidade Paris VII.

Revisão Técnica: Maria Ester de Freitas, professora do Departamento de Administração Geral e Recursos Humanos da EAESP/FGV e pesquisadora-visitante na Universidade de Paris VII.

RESUMO: Em pleno auge do individualismo, o homem nunca esteve tão encerrado nas malhas das organizações e tão pouco livre em relação ao seu próprio corpo e ao seu modo de pensar. Hoje, tudo na sociedade e nas organizações é construído para fazer o indivíduo crer na sua vocação de homem livre e criador.

ABSTRACT: Nowadays, in the highest point of individualism, it is possible to say that individual has never been so entangled in the organizations and has never been so little free regarding his own body and his way of thinking. Today, everything in society and in the organizations is built in order to make the individual believe in his vocation for being free and creative.

PALAVRAS-CHAVE: organizações, estratégia, estrutura, sociedade.

KEY WORDS: organizations, strategies, structure, society. 
Jamais na história (salvo a época da Revolução Francesa, apesar de as razões serem completamente diversas das que serão evocadas neste texto) o indivíduo ocupou um tal lugar de evidência. Nós assistimos, enfim, ao retorno massivo do individualismo e à libertação do ser humano do grilhão coletivo ("são as massas que fazem a história") ao qual ele estava até então vinculado. $\mathrm{O}$ "retorno do ator", 1 a transformação possível de toda pessoa em guerreiro, em esportista, em herói, ${ }^{2}$ indo à conquista de si mesmo, dos outros, dos mercados industriais e financeiros, fariam de nossa época um momento bendito para o indivíduo, enfim mestre de seu destino.

Este estudo, no entanto, desenvolverá um argumento contrário: jamais o indivíduo esteve tão encerrado nas malhas das organizações (em particu-
Jamais o indivíduo esteve tão encerrado nas malhas das organizações (em particular, das empresas] $e$ tão pouco livre em relação ao seu corpo, ao seu
modo de pensar,
à sua psique. to da "força da inércia" mortífera, ${ }^{7}$ ideologia tanto mais forte quanto mais a organização transformava-se, progressivamente, em instituição. ${ }^{8}$ Esses estudos não são postos novamente em questão pelas linhas que se seguem.

Eles merecem apenas ser completados. E, considerando a brevidade deste trabalho, não podem versar mais do que sobre um ponto preciso. Sendo assim, no estudo "Evaluation des hommes et structures d'organisation", 9 foram considerados três tipos de estrutura: a estrutura carismática, a estrutura burocrática (seguindo o encaminhamento proposto no início do século por Max Weber), a estrutura cooperativa (tal qual havia sido definida por Barnard ${ }^{10}$ ), que parecia ter duas vertentes: uma democrática, a outra tecnocrática, ainda que em lar, das empresas) e tão pouco livre em relação ao seu corpo, ao seu modo de pensar, à sua psique.

$O$ argumento sustentado não significa que o indivíduo não possa, dentro de certas condições, ser criador da história, ${ }^{3}$ alcançar uma "parcela de originalidade e autonomia", ${ }^{4}$ tentar sair da heteronomia e vir a ser sujeito autônomo; ${ }^{5}$ isso significa somente que tudo na sociedade (e, principalmente, na empresa, que tem a ambição desmesurada de emergir como o ator principal da sociedade) é construído para fazer o indivíduo crer na sua vocação de homem livre e criador e, para colocá-lo, de fato, "nas grades" (Rousseau), grades sutis e tão ilustres que certos homens reivindicam-nas.

Em trabalhos anteriores, ${ }^{6}$ propus uma tipologia de estruturas de organização; uma relação entre tipos de estruturas e tipos de personalidades (ou, ao menos, de conduta) exigidas; havia evocado o trabalho da morte na obra de toda organização e o papel desempenhado pela adesão à ideologia imposta pela organização, no desenvolvimen-
"Structures d'organisation et contrôle social", "11 "Structures and personnality", 12 o nome de estrutura cooperativa fosse reservado à estrutura cooperativa de estilo democrático; e uma nova estrutura, a estrutura tecnocrática fosse erigida no lugar de quarta estrutura, e a exploração de seus componentes e de suas conseqüências estivesse feita; a estrutura estratégica de gestão participativa - para retomar temporariamente o termo lançado à moda tanto por teóricos de valor, ${ }^{13}$ quanto por diretores de empresa - não havia sido ainda estudada em nossos escritos (mesmo que, desde 1984, tenham sido realizadas conferências sobre essa estrutura, na Université de Paris VII e na Université de Paris-Dauphine).

É, pois, à análise da estrutura estratégica que se dedica este artigo. Entretanto, é necessário explicar antes as razões pelas quais, desde 1961, diferenciam-se os três tipos de estrutura: a) a primeira razão é de ordem histórica e será apenas evocada. É incontestável para todos que, desde 1961, o capitalismo transformou-se frente à agita-
1. TOURAINE, A. Le retour de l'acteur. Paris: Fayard, 1985.

2. EHREMBERG, A. L'âge de l'heroisme Cahiers internatinaux de sociologie. Paris: PUF, v.85, 1988;

L'individu sous perfusion. Esprit. juilletaoût 1989 .

3. ENRIQUEZ, E. Individu, création et histoire.Connexions. n. 44, 1984.

4. FREUD, S. (1921), Psychologie des foules et analyse du moi, dans: essais de psychanalyse. nouv. td. fr. Paris: Payot, 1981.

5. CASTORIADIS, C. L'institution imaginaire de la société. Paris: Seuil, 1975.

6. ENRIQUEZ, E. Evaluation des hommes et structures d'organisation. document CEGOS, 1961; reproduit tel dans la défunte revue Gestion, 1966; remanié avec une introduction et une postface dans: Connexions. n. 19, 1976

7.ENRIQUEZ, E. Op. cit., 1984.

8. BERLE JR., A. Apud TOURAINE, A., Le tre ere dell'impresa. Milan: Uomini e technologie, 1986; idem. La société postindustrielle, Denoel, 1969. ENRIOUEZ, E. Structure et changement. La maîtrise de la croissance dans l'entreprise.Paris: Dunod, 1972.

9. ENRIQUEZ, E. Op. cit, 1961, 1966, 1976.

10. BARNARD, $C$. The functions of the executive. New York, 1938.

11. ENRIQUEZ, E. Structures d'organisation et contrôle social. Connexions. n. 41, 1982;

12. Idem. Structures and personnality, Cornell University, 1983; remanié pour la version italienne: Personalitá e organizazione, Rivista di psycologia clinica. n. 2, 1987; réécrit pour la version française: Personnalité et organisation, dans: Organisation et management en question(s). Paris: L'Harmattan, 1983.

13. TOURAINE, A. Op. cit., 1986. 
14. ENRIQUEZ, E. Op. cit., 1982.

15. 0 termo n'importe qui (não importa quem) foi proposto pelo sociólogo Alain Ehremberg, mestre de conferências em Paris-Dauphine, durante uma conversa na qual eu insistia sobre o fato de que todo mundo, na estrutura estratégica, devia acreditar na igualdade de chances. A. Ehremberg persegue, desde sua tese de 3ème. Cycle (que eu tive o prazer de orientar), intitulada "Arcanjos, guerreiros, militares e esportistas - A formação do homem forte", uma reflexão aprofundada sobre a "idade do heroísmo" e sobre as relaçōes entre o espírito esportivo e o espírito de conquista das empresas modernas. Atualmente redige (1989) uma tese nouveau régime, sob minha orientaçāo, sobre o n'importe qui. ção cultural dos anos 1968 (1965 - 1975) e às consequiências econômicas e sociais dos dois choques do petróleo. Os "trinta gloriosos" terminaram, e as empresas tiveram de fazer face a novos desafios. Além disso, o sucesso das empresas americanas e sobretudo das empresas japonesas levou certos dirigentes europeus a terem uma outra visão da direção das empresas; b) a segunda razão é de ordem teórica: desde o fim da guerra, os especialistas americanos em organizações ( $P$. Drucker, em primeiro lugar), assim como os consultores psico-sociólogos, haviam preconizado uma direção participativa das organizações, que deveria, a um só tempo, respeitar a iniciativa individual e o dinamismo do grupo, um grupo não podendo progredir nem ser coeso sem o aporte de indivíduos inovadores, sabendo escutar, discutir e tomar as decisões de forma colegiada (senão coletiva), um indivíduo não podendo atingir seu pleno desenvolvimento senão graças à confrontação de suas idéias com as dos outros. (A subjetividade não sendo mais que o produto da aceitação da inter-subjetividade). Ou, tanto quanto as estruturas tecnocráticas, à hora atual, as estruturas estratégicas assim asseguram, como a estrutura cooperativa, a participação, a ação individual e o espírito de equipe. Elas mantêm, pois, uma confusão (deliberada) nos espíritos. $\mathrm{O}$ que é preciso dizer de pronto é que suas concepções, aplicadas à realidade cotidiana, são totalmente antagônicas em relação àquelas das estruturas cooperativas, e têm desvirtuado o sentido dos termos que elas mesmas criaram com base em novas formas sociais, que de participativas só têm o nome

Para precisar os contornos da estrutura estratégica é útil compará-la com aquela que lhe é mais próxima, a estrutura tecnocrática, mesmo que ela queira, ao contrário, ser assimilada à estrutura cooperativa (tal qual esta foi definida em textos anteriores, em particular Enriquez ${ }^{14}$ ), que é a única estrutura favorável a uma participação real, excluindo todas as formas de mistificação e de manipulação.

A estrutura tecnocrática tem como credo a racionalidade ilimitada. Numa tal estrutura, o poder pertence aos experts, que supõem possuir os elementos do conhecimento, o que lhes dá a possibilidade não so- mente de resolver de maneira ótima os problemas colocados, mas, igualmente, de antecipar o seu surgimento, graças a um sistema de previsão e a um sistema de simulação (permitindo testar diferentes tipos de cenários de desenvolvimento). Os únicos problemas interessantes são aqueles quantificáveis ou susceptíveis de sê-lo (é possível também matematizar o real e inventar indicadores econômicos, sociais e mesmo afetivos, passíveis, cada um deles, de uma ponderação adequada, podendo ser elementos de um cálculo, e assim entrar num sistema de equações e inequações que um economista-matemático está em condições de resolver).

As questões de ordem política (de escolha de valores ou de objetivos) não se colocam mais; as questões relevantes são as de ordem técnica.

É possível, já que tudo pode ser programado (mesmo se existem ainda zonas de incerteza que podem ser reduzidas graças à teoria lógico-matemática das decisões, no universo do provável ou do incerto), ceder à fantasia (pois trata-se de uma fantasia) do controle praticamente total do presente e do porvir, e de evitar a ansiedade, sempre inerente às relações com o desconhecido. Experts (no poder, ou os mestres desses experts, que exercem o poder real) são, pois, definidores de modos de pensar e de modelos de ação que devem servir de normas e de regras de funcionamento.

A estrutura estratégica é outra coisa. $O$ surgimento de fenômenos que não tinham sido objeto de nenhuma previsão, a percepção da empresa e do seu meio ambiente como um mundo hipercomplexo casam mal com a idéia de uma racionalidade ilimitada e um planejamento de longo prazo.

A estrutura estratégica leva em conta a diversidade do mundo, a impossibilidade de sua apreensão total. Nessas condições, vão continuar a florescer modelos, mas estes serão, agora, adaptáveis, e levarão em grande conta circunstâncias e ações de parceiros e de adversários. O planejamento vai ser substituído pela estratégia... Ademais, essa capacidade estratégica não deve mais ser o apanágio de uma elite possuidora de conhecimentos excepcionais, mas deve, sim, ser a proeza de "não importa quem"15. Todos estratégicos, tal é a palavra de ordem. Isso é 
passível de compreensão, pois a empresa necessita de indivíduos sutis, capazes de tomar iniciativas e de reagir o mais rapidamente possível, provando leveza e flexibilidade frente aos acontecimentos imprevisíveis, constantes e numerosos com os quais são confrontados. Todo mundo torna-se um jogador, tentando ganhar e devendo ter sucesso, mesmo nas piores condições. A consequiência é uma concentração sobre as estratégias de curto prazo (enquanto a tecnocracia vivia no longo prazo) que correm o risco de ter conseqüências nefastas para a empresa (uma estratégia de curto prazo podendo ser particularmente rentável durante um certo período mostrando-se catastrófica a partir do momento em que se leva em conta um longo período). Esses jogadores estratégicos lambdas (donde o novo interesse pela teoria dos jogos, de Von Neumann e Morgenstern) não são mais pressionados a possuir conhecimentos amplos em certas áreas; eles devem ser capazes de adquirir continuamente novos conhecimentos nas áreas as mais variadas, as mais pertinentes para a empresa naquele instante t. Devem, pois, seguir as sessões de formação permanente (como mostra a multiplicação de sessões ad hoc à disposição dos quadros dirigentes e dos empregados nas empresas de ponta, que têm por objetivo fornecer "armas" para resolver a totalidade dos problemas susceptíveis de emergir), e continuar sua formação pessoalmente, estudando os novos artigos ou livros sobre administração e "resolução de problemas"; devem, pois, ser capazes de uma adaptação contínua, a fim de não serem surpreendidos por processos desconhecidos e que não estejam preparados para resolver da melhor maneira.

Em tais condições, a pesquisa fundamen- tal aparece como secundária e a pesquisa aplicada como prioritária. Esse enfraquecimento da pesquisa fundamental não é, ademais, exclusivo das empresas: as pesquisas em ciências exatas e em ciências humanas seguem o mesmo caminho. Atestam isso as ações temáticas programadas (as ATP) propostas pelos diferentes organismos ligados ao $\mathrm{CNRS}^{16}$. A questão colocada não é mais a verdade - sempre aproximativa - do conhecimento, mas seu grau de operacionalidade. $O$ resultado dessa corrida à operacionalidade é a dominação súbita de métodos e de técnicas que deveriam ser, a priori, considerados como irracionais ou aberrantes: assim, para o recrutamento de seus quadros dirigentes, as empresas farão apelo a consultores-astrólogos, a cartomantes, a tarólogos, numerólogos e grafólogos. Para que utilizar métodos sofisticados de recrutamento (entrevistas não dirigidas, entrevistas em grupo, testes de projeção) se eles não dão necessariamente melhores índices de acerto do que as técnicas de vidência e de quiromancia? Assim, para a formação e aperfeiçoamento de dirigentes serão abandonados os métodos psicosociológicos e sociológicos de formação, em troca de estágios de "sobrevivência", estágios esportivos, onde os dirigentes entregam-se ao pára-quedismo ascencional, à descida de obstáculos de uma altura de 180 metros, a raids sempre perigosos, a competições inter-empresas, numa palavra, a estágios de "aventura", buscando encontrar neles mesmos novas capacidades onde antes não se sentiam capazes (ou seja, "superarem-se"), forçados a confiar nos outros e a reforçar, desse modo, o espírito de equipe. "Um indivíduo desenvolve-se através de um outro indivíduo". ${ }^{17}$ Daniel Hémard, responsável pela Pernod-Ricard,
16. Conselho Nacional de Pesquisa Social (nota da revisora).

17. EHREMBERG, A. Op. cit., 1988. 
explica assim os objetivos desses estágios: " $A$ maioria das pessoas nas empresas são sempre subutilizadas. É preciso engajá-las na ação, incitá-las a correr riscos, dar-lhes o direito ao erro, possibilitar-lhes utilizar bem sua autonomia. Enviando-as a esses estágios, eu quero colocar os dirigentes, mas também, em seguida, os agente de controle e, porque não, os operários, em uma situação que é marcada pelo desafio, para que façam a ligação entre o engajamento físico $e o$ engajamento no trabalho" (grifo nosso). ${ }^{18}$

Podemos, por bem, perguntar-nos em que um sucesso num estágio off limits é um bom indicador de sucesso de alguém como chefe de marketing ou como responsável pela formação. Entretanto, segundo uma frase famosa pronunciada no processo que iria condenar um inocente, Dreyfuss: "A questão não será colocada".

De fato, esse tipo de estrutura persegue objetivos inconciliáveis, sobre os quais alguns dados serão fornecidos mais adiante neste texto. Exigir a integração de cada um à organização e à idealização dela mesma; demandar um espírito individualista e um forte espírito de equipe; conclamar à iniciativa e à criatividade, quer dizer, à sublimação (mesmo se a sublimação opõe-se fundamentalmente à idealização).

Outro obstáculo, e de bom tamanho: se a estrutura estratégica reclama participação não somente das elites, mas de todos, ela se desenvolve no momento mesmo em que o mercado financeiro é o mestre do jogo. Um acionista majoritário, um novo grupo conquistando o seu OPA, um raider que torna sua operação bem sucedida podem balançar as estruturas da empresa, demitir mesmo os "empregados" mais fiéis e os mais íntegros, fazer desaparecer departamentos inteiros, desmembrar a empresa, vender partes ou o conjunto da organização a um desconhecido etc. Ser fiel, leal à empresa, ser um bom estrategista, ter acumulado conhecimentos pertinentes, não serve, às vezes, para nada, senão para fazer parte da primeira fornada de demitidos ou aposentados, os novos proprietários da empresa não podendo deixar de suspeitar dos membros particularmente leais à velha empresa. Prova disso é a resistência sempre desesperada de todas as categorias de trabalhadores, que se manifestam mais e mais freqüentemente diante das práticas totalmente imorais, o que leva certos patrões, eles mesmos, a reclamar regras para o jogo e a definição de uma ética, as quais acabam por dar uma aparência "amável" ao capitalismo selvagem do século XIX.

Entretanto, apesar dessas tentativas de resistência, ou ao menos de reticência, os administradores de alto nível e a maioria dos dirigentes deixam-se seduzir pela miragem da estrutura estratégica, mistura sutil do modelo japonês, privilegiando os esforços coletivos e não reconhecendo o indivíduo senão como membro de um grupo do qual ele aceita as normas (ademais, o termo "grupismo" é de origem japonesa), e do modelo americano, privilegiando o esforço individual e o sucesso pessoal (Um tal casamento é viável? Não é explosivo? Esse ponto será evocado na conclusão). A estrutura estratégica vai, portanto, exigir a "qualidade total" (a "falha zero") de seus produtos, de seus serviços e de seus homens, pois, como dizem os consultores americanos: total quality is a survival. Uma empresa deve sobreviver, ${ }^{19}$ conquistar novos mercados, alcançar uma potência ilimitada, eliminar, se possível, seus concorrentes. Para atingir um tal objetivo, ela precisa de indivíduos que sejam simultaneamente grandes tomadores de decisão, grandes comunicadores, grandes persuasores; tendo igualmente necessidade da participação ativa de todos (daí o desenvolvimento de grupos de expressão, de círculos de qualidade, de grupos de projetos, de grupos de progresso, de grupos ad hoc de resolução de problemas). "Todos no ponto" é a palavra de ordem da empresa estratégica.

Definida - ainda que sumariamente - a estrutura estratégica, é preciso agora - nosso propósito essencial sendo o de examinar como o indivíduo é preso nessa armadilha - analisar mais de perto os tipos de personalidade exigidos, as instâncias da personalidade postas em prática, os pólos da personalidade que são destacados, o destino das pulsões e a concepção de trabalho coerente com essa estrutura.

Uma observação restritiva é indispensável (observação, aliás, já evocada em nossos textos de 1982 e 1983). Não se trata de 
chegar a uma radiografia fechada, a uma caracterologia precisa; o objetivo é mais modesto. Trata-se simplesmente de mostrar que as empresas têm uma tendência a engajar pessoas cujos comportamentos são adequados ao estilo da empresa, ou quando elas não podem ser assim, transformá-las (pelo trabalho, pela pressão de grupo, pela ideologia dominante na empresa, pelos estágios de formação) em indivíduos que, ao menos exteriormente, façam prova das qualidades que favorecem o crescimento da empresa.

Tipo de personalidade: a estrutura tecnocrática não poderia funcionar senão graças a seus experts, "elite dirigente" demonstrando qualidade de manipuladores e colocando-se numa posição perversa. ${ }^{20}$ Não podendo todo mundo jogar um tal jogo, controlar zonas de incerteza ou adquirir poder segundo a fórmula de Crozier, sem fazer da empresa uma verdadeira selva, revelava-se indispensável que essa elite regesse uma massa de indivíduos indiferentes (fazendo apenas seu trabalho), desmotivados (cumprindo ordens sem se interrogar sobre os valores, pois não têm como referência nenhuma valor particular) ou rebeldes (na medida em que uma empresa tecnocrática podia admitir uma porcentagem limitada de desviantes e de rebeldes capazes de trazer novas idéias, aproveitáveis, em parte, pela empresa).

A estrutura estratégica não pode funcionar da mesma maneira, como foi explicado anteriormente. Ela exige de todos esses homens serem "estratégicos", "guerreiros", "ganhadores", 21 esportivos; numa palavra, aquele que temos chamado de "matador cool". ${ }^{22}$ Max Weber tinha, há muito tempo, assinalado que uma vez que a dinâmica capitalista não estava mais fundada sobre uma ética, ela não podia desenvolver senão suas características puramente primárias e seus aspectos esportivos, valorizando a perfor- mance pela performance. Esses matadores (diz-se dos esportistas de alto nível, assim como dos políticos que não hesitam diante de seus objetivos, que são "matadores") são cool pois, como bem o dizia Sade, devem conhecer "o repouso das paixões e a dormência da sensibilidade" que os levarão a cometer os atos mais criminosos, os mais aberrantes, os mais expressivos da traição com fleugma, "com essa apatia que permite às paixões revelarem-se”. Não é, pois, questão de eliminar um adversário ou um concorrente com paixão, é preciso fazê-lo, ao contrário, com doçura (e não matálo definitivamente, pois ele pode, um dia, talvez, revelar-se útil). O matador cool ou apático, para atingir os seus fins, deve praticar uma certa forma de ascetismo (como na ética protestante), um ascetismo não somente do pensamento, mas do corpo. O corpo deve ser refeito, ele deve ser endurececido. É a esse novo ascetismo que servem os estágios off limits, como foi questionado aqui antes. Com efeito, a empresa estratégica tem, por fundamento, uma equação simples: energia física = energia psíquica $=$ aptidão para $o$ sucesso individual = aptidão à utilidade social.

Em outros tipos de estrutura foram valorizados um controle do pensamento, um controle da psique e, igualmente, um controle do corpo (este último tipo estando reservado essencialmente aos operários, sendo o ritmo e o estilo de trabalho definidos pelo setor de aplicação de métodos, impondo a adaptação do corpo, com todas as consequiências nefastas: doenças profissionais etc., que podem disso resultar). Na estrutura estratégica, se o controle sobre o modo de pensar é reforçado (é preciso pensar apenas no bem de uma empresa e um tal objetivo não é alcançável senão graças a um modo de pensar puramente operacional, "calculista", diria Yves Barel), se o controle da psi-
20. ENRIQUEZ, E. Le pouvoir et la mort. Topique. n. 11-12, 1973

21. AUBERT, N.; PAGES, M. Le stress professional, Klincksieck, 1989.

22. ENRIQUEZ, E. Ideology, idealisation and efficacy. International society for the psycho-analytic study of organizations. 1986. 
que torna-se mais e mais sutil (os indivíduos identificando-se com a empresa e com seus chefes e idealizando-os, tornando-se, assim, "serviçais voluntários" que encontram o gozo na submissão), o controle sobre o corpo (e, em particular, o dos dirigentes) torna-se essencial. Um dirigente frágil, com problemas, que não se sente bem na própria pele, é incapaz de se superar fisicamente e de controlar seu corpo (de controlá-lo totalmente) não pode ser mais que um looser (um perdedor) do qual a empresa deve-se livrar o mais rápido. Assim, o controle social torna-se total ou cede à fantasia do totalitarismo, ainda que o controle total não tenha jamais existido (felizmente, salvo em casos raros: campos de concentração).

Nosso matador cool, se conservou características perversas (pois a apatia é a expressão mais adequada da perversão), deve, além do mais, saber fazer prova de teatralidade. Todo poder é um "poder no palco", todo poder se exprime em posturas majestosas, roupas suntuosas, festas, opulência, extravagância; numa palavra, sua própria representação, visando surpreender as massas. A estrutura estratégica, mais que outras, exige um reforço da teatralidade. O chefe deve poderse mostrar, impressionar seus colaboradores, demonstrar magnificência, fazer ressaltar suas marcas de sucesso (não esqueçamos que o jogo das aparências é um elemento essencial da idade barroca; ora, nós vivemos numa época de "barroco degenerado"). ${ }^{23}$ Certos líderes políticos compreendem bem: Mitterand com a sua reunião dos Sete Grandes, em Versalhes, em 1982, e com as manifestações do bicentenário e a reunião dos Sete Grandes, sob a pirâmide do Louvre e no Arco de La Défense, é um exemplo perfeito do homem que sabe utilizar a teatralidade em seu maior proveito. Num nível mais modesto, um Bernard Tapie (diretor de empresa, presidente do Olympique de Marselha, deputado) conhece perfeitamente a melhor maneira de estar em cena e valorizar-se. Na Itália, Berlusconi (sobre o qual os italianos fizeram um filme notável) sabe valorizar-se, fazer rir sua platéia, fazer charme, adular, seduzir e provocar aplausos generalizados.

Essa teatralidade não é possível sem que nosso ganhador manifeste um comportamen- to "histérico", quer dizer, suceptível de erotizar a seu modo as relações sociais (o histérico não pode conceber relações sociais não erotizadas) e, para alcançar essa meta, ele se mostra como justo e sensível, como duro, implacável e compreensivo, como misterioso e extraordinariamente próximo. Ele integra na sua conduta fálica (é um verdadeiro homem, é um exemplo, é um chefe, é um Deus, ou um super-Deus, escreve, ironicamente, Le Canard Enchaîné sobre Mitterand) o modelo feminino ${ }^{24}$ ou o que os homens nomeiam assim, dando-lhe há muito tempo um tom pejorativo: dito de outra forma, a capacidade de bem falar, saber convencer, sorrir e seduzir. Os tempos não são mais do chefe que comanda, mas daquele que seduz, persuade, exala charme, anima e sabe jogar com as aparências. Nossa sociedade - Baudrillard tem feito ver fortemente já há muito tempo - é uma sociedade onde a aparência triunfa. É, pois, a sociedade perfeita para todos aqueles que sabem usar a "histeria" com plena consciência. Atenção! Não se trata de dizer que essas persunalidades são, no seu foro íntimo, histéricas. Basta, já que a aparência vale mais que a realidade e a mentira que a verdade, conduzir-se exteriormente assim. O que são esses seres por trás da fachada, disso nós não temos a mínima idéia. Eles fazem o que é preciso para que o mistério perdure. $\mathrm{E}$, de todo modo, isso não tem a menor importância. A máscara, a persona, substitui a pessoa. Tente saber o que pensa realmente um japonês e você compreenderá rapidamente que o essencial está no exterior, na superfície, e é apenas a superfície que conta.

Instâncias da personalidade postas em prática. Na estrutura tecnocrática, prevalece no nível do top management os indivíduos de "ego forte" sem états d'âme, ${ }^{25}$ que sabem programar suas atividades e adotar ações corretivas necessárias. Essa elite domina indivíduos indiferentes, sem pontos de referência, que não têm mais que um "ego flutuan$t e$ ", todo mundo não podendo e nem devendo jogar o jogo dos tecnocratas. Eles representam a imagem invertida dos tecnocratas. São pequenos perversos, instrumentalizando os outros e o mundo segundo seus meios limitados, enquanto os tecnocratas são grandes perversos, transformando todas as rela- texto, no sentido de sem estados de espirito, sem humores variáveis, sem emoçōes. (N.R.). 
ções humanas em relações operacionais, desafiando o real, tendo uma visão estritamente econômica e "economicista" das trocas sociais, e instalando-se no lugar da verdade.

A estrutura estratégica não põe em prática (ou, em todo caso, não da mesma maneira) as mesmas instâncias da personalidade. Ela exige indivíduos que se querem sujeitos (mas que, de fato, são alienados) de seu destino e agentes da história. Sujeitos presos nas identificações heróicas e aptos a se comportarem como heróis, quer dizer, como seres prontos - como Freud havia sublinhado ${ }^{26}$ - a introduzirem rupturas, e mesmo a prepararem os outros, que lhes devotam admiração sem limites, merecida por todo ídolo. Aqueles que são bem sucedidos têm, pois, um "ego grandioso" (o "Ego grandioso" de Kernberg), tomam-se eles mesmos como ideal, são verdadeiros Narcisos admirando-se no espelho que eles propõem e que os outros lhes servem, têm uma "identidade compacta", pois nada pode atingi-los. Não conhecem, com efeito, nem dúvida, nem angústia, nem remorso. Essa identidade compacta, essa sinuosidade narcisista, não os impede, entretanto, de mostrarem-se leves, flexíveis (ao contrário do tecnocrata que acredita possuir a verdade). Eles sabem que para alcançar o sucesso devem poder adotar identidades múltiplas (ser aqueles que podem escutar, falar, atrair, mostrar ardor, exprimir a própria vontade, seduzir) segundo as situações e os interlocutores. Homens da aparência, modulam seu papel social segundo as circunstâncias. São sempre no instante aquilo que devem ser para ter sucesso. Identidade compacta e identidades múltiplas não se opõem, elas são complementares uma da outra. Pode-se dizer, como Winnicott, que eles têm um faux self. Entretanto, a noção de falso self recoloca a possibilidade de possuir um verdadeiro self. É, pois, mais exato seguir Hélène Deutsch quando ela fala de personalidade " as if" (como se) pois esses indivíduos comportam-se sempre "como se" estivessem bem na própria pele, como se amassem realmente os outros etc. É, às vezes, possível vencer um tecnocrata; é muito difícil vencer uma personalidade as if, possuidora de um ego grandioso, na medida que ela sabe adaptar-se a todos os desafios do ambiente, onde manifesta como identidade tão somente a sua identidade social.

Ela é um verdadeiro Proteu, sempre insaciável. (Os estágios de análise transacional ou de programação neuro-linguística, muito em voga atualmente, ajudam-na em seus esforços de adaptação, pois fornecem-lhe elementos simplificados de controle do comportamento do outro).

Ela - a personalidade "como se" - é tão bem sucedida quanto mais contrária ao tecnocrata; ela aceita ter pulsões, pulsões de amor ou de agressividade. Mas dessas pulsões (como de resto) tenta servir-se (vivendo, assim, a fantasia extrema do controle possível, pelo indivíduo, do seu inconsciente). Acredita, pois, ter à disposição um “id integrado". Jogará com a cólera, com a violência, assim como com a doçura e a ternura, pois na estrutura estratégica não há necessidade de seres impassíveis mas de seres capazes de encarnar as
26. FREUD, S. (1939), L'homme Moise et le monothéisme. nouv. trd. fr. Paris: Gallimard, 1987. 
paixões, para poder provocar o entusiasmo ou o medo que dinamiza os "grupos".

Ela ganha tanto mais a confiança dos outros quanto mais não se pretende (como a tecnocrata) ser a única a poder cumprir aquilo que faz. Todo indivíduo pode fazer tão bem quanto ela à condição de querer, ele também, superar-se e aprofundar-se. "Se eu sou formidável, você também pode vir a ser formidável". (Um Tapie, um Berlusconi pronunciam à exaustão uma tal frase). "Eu não era ninguém, eu me fiz a mim mesmo e você também pode se transformar". Assim, a megalomania torna-se uma coisa melhor partilhada! Como não se fascinar por um ídolo que lhe diz, democraticamente, que basta querer para poder e que você tem, você também, como o diz Tom Wolfe, "o estofo de um herói" e a estatura de um ídolo?

Assim, as instâncias postas em prática são o ego (por vezes grandioso, compacto, flexível, "protéico", democrático) e um id integrado, dotado por esse ego "em facetas".

Pólo da personalidade destacado. A estrutura carismática mostra o desejo de realização de si mesmo; a estrutura burocrática, o desejo de redução das tensões; a estrutura cooperativa, a comunicação com os outros, aos quais se reconhece uma alteridade irredutivel. A estrutura tecnocrática reconhece também a existência do outro, mas somente como objeto manipulável e instrumento à sua mercê, quando ela não o nega (o outro tornando-se um objeto descartável quando não serve mais) ou quando ela não o destrói, sem se dar conta e acreditando, além do mais, agir para o seu bem (o perverso sendo sempre aquele que sabe melhor que o outro as fontes do prazer - ou do gozo - deste último).

Para a estrutura estratégica, o outro existe realmente. É preciso, pois, conhecê-lo (daí os estágios de formação para o conhecimento e o controle do outro), dar-lhe a impressão de ser respeitado, de ser valorizado. $\mathrm{O}$ outro é uma peça-mestra do gerenciamento estratégico participativo (elemento central da estrutura estratégica), já que a empresa necessita para sua sobrevivência ou o seu crecimento de capacitação e de integração Pouvoir re poli, RAMANANTSO ture politique d'entre prise. McGraw-Hill, 1985
É, pois, necessário comunicar-se com o outro (os grandes tomadores de decisão são, ao mesmo tempo, grandes comunicadores), extrair o máximo do seu potencial. Para isso, a sedução é a conduta mais bem adaptada. Sedução que se exprime em uma animação leve da equipe de trabalho. Essa animação tem por meta dar à equipe o sentimento de cumprir uma grande obra. "Colaborem comigo... nós vamos construir juntos o projeto..., suas idéias são indispensáveis..., a empresa é a catedral do mundo moderno". De fato, trata-se - pelo viés de uma identificação com o sedutor, promovido ao status de ídolo - comumente, de um verdadeiro estupro psíquico.

A comunicação (como na estrutura cooperativa) torna-se a preocupação permanente de cada um. Porém, enquanto na cooperação a comunicação podia exprimir as dúvidas, os remorsos, a ansiedade, ou seja, os sentimentos das pessoas vis-a-vis de seus "alter ego" ou dos problemas a estudar, e pôr em causa a regulação do grupo, a comunicação estratégica deve ser afirmativa (assertiveness). Ela deve exprimir a capacidade do indivíduo de colocar e resolver os problemas, sua vontade inabalável para fazêlo, e deve melhorar a coesão e o rendimento da equipe. A comunicação interna deve, naturalmente, ser acompanhada por uma comunicação externa. Comunicação que tem por meta realçar o prestígio da empresa diante de sua clientela, e aumentar a sua base; comunicação que tem igualmente por objetivo (e isso não é pouco), dar lugar a verdadeiras estratégias racionai ${ }^{27}$ com as comunidades locais, os poderes públicos e, principalmente, com os parceiros potenciais: uma empresa provando da dificuldade de controlar sozinha um mercado ou uma atividade. É importante notar que a desconfiança (inerente a toda conduta estratégica) rege o comportamento dos atores. Um aliado é sempre temporário, ele pode se transformar em adversário convicto ou em traidor, antes de voltar a ser um parceiro amável que, num dia de distração, golpeará seu novo amigo pelas costas [Basta considerar as peripécias da tentativa de controle da Société Générale de Belgique pela Cerus (De Benedetti: A. Minc), associados (!) Hersant-Berlusconi, Bouygues-Marxwell, da 
interferência de B. Arnaudt sobre a VuittonMoet-Hennessy, ainda que ele tenha sido chamado para ajudar na manutenção da equipe no lugar...]. Os amigos não existem mais, os adversários irredutíveis tampouco. No universo da estratégia, não podem ter êxito senão as relações de negócios, e elas exprimem a força de cada um dos parceiros em um dado momento. Os comunicadores continuam sempre grandes "matadores", frios e resolutos.

Destino da pulsões. Na estrutura tecnocrática, a libido dessexualizada é investida no trabalho produtivo, a pulsão de morte exprime-se pela crueza da Ética à qual todos os membros são submetidos e a pulsão da agressão é dirigida ao exterior. Na estrutura estratégica, como o desenvolvimento precedente o mostra (também aqui seremos breves), a libido é ressexualizada (erotização das relações), ela não é mais canalizada somente para o trabalho, mas favorece a identificação, a coesão social (o espírito de equipe). O indivíduo deve-se conduzir como um ser de paixão - afirmando sua virilidade e sua força física (mesmo se se tratar de uma mulher) e acreditando possuir o falo (como se a posse do falo fosse uma missão possível!) - e, ao mesmo tempo, como um ser da palavra (ele seduz, ele atrai, ele engana). Assim, obtém-se a mobilização geral das energias (se os membros da organização comportam-se bem como corpos, psiques, intelectos a serviço da cultura e do imaginário da organização ${ }^{28}$ ).

Quanto à pulsão de morte, ela parece "domesticada": o matador é cool, os conflitos internos são reduzidos, pois se a racionalidade política não tem medo dos conflitos, a racionalidade técnica e estratégica evita-os fortemente. Apenas devem retardar a emulação e a competição (normais no seio da empresa onde reina a ideologia frágil do consenso). Quanto aos adversários exteriores, eles não devem mais ser eliminados definitivamente, pois podem se revelar úteis um dia. Entretanto, isso é apenas aparência: de fato, como o mostrou magistralmente Yves Barel, ${ }^{29}$ a vontade de auto-referência é criadora de duplos. Duplos nos quais cada um projeta sua parte diabólica, que ao mesmo tempo, são objeto de repulsão e de fascinação, pois são suficientemente parecidos para representar a "parte maldita" (o inimigo) que repousa no foro interior de todo ser. (Nós já tínhamos tentado ${ }^{30}$ marcar a oposição e a conivência que existiam entre judeus e alemães; A. Codaccioni ${ }^{31}$ recentemente mostrou o papel da imagem do mouro, objeto de apropriação e de rejeição para a constituição da identidade corsa). Esses duplos, é preciso abatê-los. Entretanto, eles provocam inveja. A inveja é o único dos pecados capitais que não propicia nenhuma satisfação no imediato. Ou, a inveja, contrariamente à tese de J.P. Dupuy e P. Dumonchel, ${ }^{32}$ não constitui um motor econômico. Ao contrário, ela freia o desenvolvimento, pois o sucesso de uns lesa interesses de outros, como havia estabelecido G.M. Forster; pois ela não pode provocar senão a morte do outro e de seu desejo. Isso torna, pois, tão importante fazer com que o outro fracasse num negócio, quanto realizar um. Donde esses "golpes atravessados", essa espionagem generalizada no mundo industrial e no da administração, esse espírito de delação (pede-se a dirigentes recrutados pelos "caçadores de talentos" que revelem todos os segredos que podem conhecer de sua antiga empresa), de corrupção sem freio, a que nós assistimos, e que estão longe de levar à criação de novas riquezas. Nós tínhamos, no tempo, ${ }^{33}$ caracterizado o capitalismo como o mundo da corrupção generalizada (o caso do Japão é exemplar, desse ponto de vista), e o universo totalitário como aquele da delação generalizada (cada um devendo denunciar os inimigos do povo). Nós devemos, dizer hoje que esses dois comportamentos tendem a se parecer ao menos num ponto: os países que podemos ainda chamar de totalitários são presos igualmente no ciclo da corrupção em larga escala (URSS e China, para citar apenas os maiores), os países capitalistas praticam a delação (cada um podendo ser denunciado como um "fraco", um "incapaz" freando o crescimento da empresa). Sabe-se, desde a noite dos tempos, que é mais fácil conjugar os vícios que as virtudes. A pulsão de morte está longe de ser domesticada. Ela raramente teve um tal espaço onde exercer sua força devastadora [o individualismo (a
28. ENRIQUEZ, E. L'imaginaire social, refoulement et répression dans les organisations. Connexions. ก. 3, 1972.

29. BAREL, Y. La ville médiévale. Paris: PUF, 1980.

30. ENRIQUEZ, E. De la horde à l'Etat. Paris: Gallimard, 1983.

31. CODACCIONI, A. Territoire(s) et production de l'espace. thèse d'Etat, 1989.

32. DUPUY, J.P; DUMONCHEL, P. L'enfer des choses. Paris: Seuil, 1982. 
33. ENRIQUEZ, E. Bureaucratie ou autogestion, Supplément à Recherches socialistes. n. 5-6, 1974.

34. SAINSAULIEU, $R$. (sous la direction de, L'entreprise en société. Paris: Fond Nat. des Sciences Politiques et Inter-Editions, 1990. Este livro foi lançado em 1990 com o título: L'entreprise - une affaire de société. (N.R.) auto-referência) sendo capaz de criar duplos em profusão] e a destruição toma o caminho da produção.

Concepção do trabalho. A estrutura tecnocrática visava apenas a produção sob todas as suas formas, ela preconizava a guerra econômica, forma moderna da guerra total. Era governada pela estrita lógica comercial. A empresa era uma sociedade de combate.

A estrutura estratégica é a expressão de uma empresa que quer ser ao mesmo tempo uma comunidade, comunidade de trabalho, mas também comunidade da vida e do pensamento. Ela se apóia sobre o indivíduo integrado a uma equipe. $O$ trabalho não tem um sentido a não ser que lhe permita a um só tempo coesão e performance. (Daí os diversos apelos à expressão e à comunicação, enfatizados anteriormente).

A guerra é total, mas ela pode ser mais amortecida (estratégias racionais) ou, ao contrário, mais violenta (OPA, raiders...) que na estrutura tecnocrática. $O$ sorriso é violência potencial; a violência, o detonador possível de uma combinação frutífera. Quando a produção não tem mais resultados esperados, as firmas reforçam suas atividades financeiras. (É o caso da Ford, atualmente, e das empresas japonesas em geral, que aumentam o seu império sobre o mercado de capitais. Basta apenas notar que a predominância do capital financeiro sobre a produção foi iniciada há mais de dez anos, mesmo na França). A meta não é mais o investimento industrial, é o "golpe" financeiro. Max Weber não reconheceria mais seu mundo: trabalhar não enriquece mais, ou muito pouco. Apenas a especulação engendra dinheiro. A famosa fórmula de Marx: D (dinheiro) $\rightarrow$ M (mercadoria) $\rightarrow$ D' (dinheiro) está obsoleta. $O$ dinheiro permite fazer dinheiro sem produção de mercadorias.

\section{Alguns destaques finais}

Ficando este trabalho mais longo do que o previsto, contentamo-nos com alguns destaques (para mais informações ver a obra de 1990 sob a responsabilidade de $R$. Sainsaulieu: L'entreprise en société,$^{34}$ na qual nós assinamos um estudo: "L'entreprise comme lien social: un colosse au pied d'argile").
1. A empresa estratégica tem, cada vez mais, estratégias de curto prazo. À força de jogar no curto prazo, estrutura-se o mundo sob este aspecto. Ora, Sylvain Trinh já o demonstrou, a estratégia de curto prazo não é uma verdadeira estratégia. Os japoneses compreenderam-no tão bem que jogam todas as forças na realização de um objetivo único sobre vários anos. É assim que eles puderam estabelecer um quase-monopólio de produtos (ex: motos, fotos...) sobre os quais outros países detinham um avanço considerável.

2. As estratégias mais financeiras que produtivas, findaram por desestabilizar o mercado. As "desregulamentações" selvagens fazem do capitalismo avançado uma verdadeira selva, que provoca o medo de certos diretores de empresa que reivindicam um retorno à "Ética" ou, pelo menos, às regras do jogo aceitas por todos.

3. A empresa estratégica quer a participação de todos. De fato, não é mais que uma elite quem desfruta da adesão massiva à dinâmica organizacional. Para a maioria, o trabalho torna-se menos interessante, o risco de desemprego cresce, a precariedade do trabalho aumenta, as promoções são bloqueadas. Fala-se tanto mais de participação quanto na realidade a possibilidade e o desejo de participação diminuem. A "histeria", a "teatralidade" encontram seus limites. O mundo das aparências começa a aparecer como um mundo de mistificação.

4. Mesmo a elite não está mais segura de si. Os esforços, o talento, a identificação com a empresa não impedem a demissão dos dirigentes e empregados, as empresas desaparecendo ou estão sendo compradas.

5. Quando equipes formam-se e adquirem uma forte identidade, os administradores já não ficam tão felizes, pois essa identidade parcial, dando aos indivíduos e aos grupos uma nova força de proposição e de contestação, pode pôr em xeque a coesão da organização, que se vê como um sistema cultural, simbólico e imaginário, do tipo totalitário. J. Dubost insiste, com muita propriedade, sobre "as ambivalências da gestão em face das formações identitárias”. 
6. Mais e mais numerosos são os administradores que, compreendendo o que lhes pode acontecer, vêm a conceber estratégias pessoais de carreira, e estão aptos a deixar sua empresa por uma outra que lhes ofereça salários e possibilidades de promoção mais interessantes. O "Ego grandioso", o "narcisismo", voltam-se contra a empresa.

7. Além do mais, mesmo se a empresa conseguir integrar o pessoal e fazê-lo aceitar seus ideais, ela não poderia provocar senão a idealização. Ora, a idealização propõe um objeto maravilhoso que não pode ser colocado em questão, que procura um estado psíquico de nãoconflitualidade e uma retomada narcísica. A idealização desenvolve o "fanatismo de empresa" (expressão de E. Morin). Ora, o fanatismo não é criador de nenhuma idéia nova, ele se contenta em defender a causa. Assim, será capaz de copiar, às vezes de aperfeiçoar, idéias ou produtos existentes (os japoneses passaram a ser mestres na matéria), mas não estará apto a fazer prova de inovação. A inovação implica a possibilidade de sublimação - quer dizer, a capacidade de colocar-se novos problemas interiormente (in interiorité) - a possibilidade de fazer prova de imaginação realizadora, para retomar a fórmula de G. Palmade, a possibilidade de conhecer a dúvida $\mathrm{e}$ compreender que os momentos de angústia profunda (de depressão, às vezes) são elementos necessários à criatividade, à construção de objetos ou de relações amadas por eles mesmos, pelo aspecto estético e lúdico de que se revestem. A criatividade exclui, pois, as estratégias racionais, o jogo com a aparência. Ela engaja a vida de cada um. A empresa gostaria muito que as pessoas engajassem sua vida, mas para seu próprio lucro. Pois, como formula tão bem o poeta metafísico inglês John Donne: "Cada homem é uma ilha", e cada homem não pode ser criativo se não sente no mais profundo de si mesmo a vontade de construir o inteiramente novo. Ele poderá fazê-lo com os outros, mas à condição de que estes sejam os "outros" com os quais ele possa construir verdadeiras relações de amiza- de e de confiança (cf. os pintores impressionistas e pós-impressionistas). As empresas têm medo de uma tal criatividade. Elas não se querem dar conta de que só deixando a seus membros a possibilidade de sublimar, permitir-lhesia (à condição de não tentar mistificá-los) trazer para a empresa (e a eles mesmos, em primeiro lugar) a inventividade que elas reclamam aos quatro ventos.

8. Atualmente, as empresas de estruturas estratégicas não podem levar seus trabalhadores senão a uma usura mental provocada pela carga psíquica desmesurada dedicada à manutenção da função ocupada, e que os coloca em um doublebind constante que faz com que, não importa o que cumpram a longo prazo (salvo para alguns eleitos), eles terão errado. Os colaboradores são, pois, submetidos a constante "stress profissional", e não se podem manter senão graças à absorção massiva de psicotrópicos. Eles tornam-se, então, "indivíduos sob perfusão". ${ }^{35}$

9. A idéia de criar empresas que tomam emprestado do modelo nipônico e do modelo americano o que eles têm de melhor (fantasia desenvolvida pelos que crêem na "empresa do terceiro tipo") - o pertencimento ao grupo e a iniciativa individual - revela-se aberrante, pois essas duas culturas possuem identidades pronunciadas e um patchwork entre elas não seria, como dizem os alquimistas, senão o casamento impossível entre a água e o fogo (mas a demonstração demandaria mais amplos desenvolvimentos).

10. Enfim, não esqueçamos que, como escrevia A. Schnitzler, "a alma é uma terra estrangeira/estranha”, e que, sendo assim, apesar das numerosas armadilhas semeadas pela estruturas estratégicas, levantar-se-ão sempre os indivíduos que, conscientes de sua estranheza, do aspecto labiríntico de sua alma, preferirão as alegrias (e as angústias) que expressam o fato de serem sujeitos pensantes e falantes, ao invés desses "balões" um pouco já murchos que lhes revelam as estruturas estratégicas.
35. AUBERT, N. e PAGÉS, M. Op. cit., 1986.

36. EHREMBERG, A. Op. cit., 1989.

RAE • v. 37 • n. 1 • Jan./Mar. 1997 